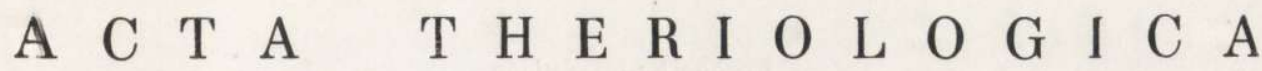 \\ VOL. X, 8: 107-109. \\ BIAŁOWIEŻA \\ 15.VIII.1965
}

\author{
E. DOTTRENS
}

\section{Sur la réintroduction des Castors en Suisse}

\author{
Castoriana II.
}

Les castors ont été réintroduits en Suisse des 1956. Les premiers individus capturés dans le bassin du Gard ont été d'abord enfermés dans un enclos, puis ensuite, libérés. A fin 1962 , on estimait à 10 ou 12 individus la petite colonie. D'autres introductions ont été faites depuis, avec succès semble-t-il, malgré quelques pertes.

La réintroduction de castors en Suisse tentée dès 19506, s'est révèlée une entreprise hérissée de complications tant administratives que pécuniaires.

La tentative dépendait tout d'abord de la permission des autorités françaises de capturer des castors dans le département du Gard. Moyennant diverses démarches, elle fut accordée gracieusement. Il fallut aussi solliciter l'assentiment des autorités cantonales et fédérales. Les autorisations nécessaires furent obtenues dès que le Ligue Suisse pour la Protection de la Nature, surtout, eut fourni les garanties financières exigées et accordé l'argent nécessaire à la couverture des frais de capture et d'installations d'un enclos utilisé au début. Le désintéressement et la générosité des participants aux expéditions de capture et aux travaux de protection fit le reste. 11 fallut trois expéditions pour ramener huit castors en tout. Les premiers furent enfermés dans enclos, mais quand fut acquise l'autorisation du Conseil fédéral de lâcher nos hôtes en liberté, en janvier 1958 , l'enclos fut ouvert et plus tard supprimé. Malgré les vicissitudes inhérentes à une telle entreprise, la réacclimatation des castors en Suisse paraît en bonne voie. Les quatre individus survivants, libérés on 1958, se sont déplacés en amont et vers l'aval, parcourant la contrée, remontant niême d'autres cours d'eau. Au printemps 1958, ils paraissaient avoir fixé leur choix. Deux d'entre eux restèrent d'abord sur territoire genevois, on n'entendit guère parler d'eux au début. Les deux autres ont formé un premier couple, se sont installés dans la région des marais de Divonne, là 
cû la Versoix devient rivière frontière. La grande sensation de 1958 fut la découverte, fin juin, d'une hutte construite par ce couple sur territoire français, mais à quelques dizaines de mètres de la frontière. Les observations en 1959 apportaient successivement deux nouvelles joies aux dévoués initiateurs: d'abord la découverte d'une hutte sur territoire vaudois, €n aval de la première, puis, en juillet, la certitude que la femelle y avait donné naissance à deux petits qui prospèrent à merveille et qui ont été vus depuis par plusieurs naturalistes.

L'enthousiasme de la réussite probable était cependant tempéré par les difficultés résultant de l'activité de nos premiers castors réacclimatés. Ils commirent des dégâts en abattant des arbres. S'ils s'étaient contentés des aulnes et des saules des bois riverains, personne ne s'en serait plaint sérieusement, malheureusement, ils ont abattu force peupliers de culture et même un ou deux arbres fruitiers. Il a fallu prendre d'urgence des mesures pour mettre les essences de rapport à l'abri de leurs terribles cisailles. L'expérience montra qu'il suffisait d'entourer d'un treillis métallique la base des arbres à protéger. Il importa aussi d'indemniser équitablement les propriétaires lésés.

Depuis cette premiere tentative, couronnée de succès, malgré quelques pertes, d'autres introductions ont eu lieu en Suisse qui paraissent en bonne voie dans le canton de Neuchâtel et dans le canton d'Argovie.

Dès 1959, les observations des individus acclimatés sont devenues plus difficiles, non seuiement ils ont cessé de se manifester par des dégâts, mais encore ils ont appris à mener une vie plus discrète construisant moins et creusant semble-t-il des terriers difficiles à déceler. Le décompte des individus nés chaque année est pratiquement impossible. Mais les indices que la petite colonie prospère normalement sont encourageants. A fin 1962, on croit que le contingent pourrait comprendre 10 à 12 individus répartis sur une dizaine de kilomètres de rivière et qu'il existe deux familles.

En octobre 1962 une nouvelle expédition, autorisée par le Service des Eaux et Forêts de France, a capturé un nouveau couple qui fut amené aussitôt en Suisse pour être installé dans l'Areuse, canton de Neuchâtel. Un de ces animaux a été. victime d'un accident survenu après quelques jours seulement. L'expérience sera certainement poursuivie. D'autres réintroductions sont prévues dans une ou deux rivières du Jura suisse.

\section{BIBLIOGRAPHIE}

1. B la n chet, M., 1960: Note sur les Castors du Bassin méridional du Rhône, et premiers résultats d'une tentative de réintroduction de l'espèce en Suisse. La Terre et la Vie, Revue a'Historie naturelle, 1 : $1-43$. Paris. 


\section{Э. ДОТТРЕНС}

\section{РЕАККЛИМАТИЗАЦИЯ БОБРОВ В ШВЕЙЦАРИИ}

Р е $з$ ю м е

В 1956 году вновь акклиматизировано в Швейцарии бобров привезенных из Франции. Восемь особей помещено в одном загоне. В 1958 году их выпустили на свободу. В 1962 году численность бобров в Швейцарии состовляла вероятно 10-12 особей. Эти опыты будут продолжаться.

\section{E. DOTTRENS}

O PONOWNYMI WPROWADZENIU BOBRA W SZWAJCARII

\section{Streszczenie}

Bobry ponownie wprowadzono do Szwajcarii $N 1956$ roku, sprowadzając 8 sztuk z Francji. Zamknięto je w zagrodzie a w roku 1958 wypuszczono na wolność. W końcu 1962 roku było już prawdopodobnie 10-12 osobników. Obecnie kontynuuje się dalsze prace związane $\mathrm{z}$ ponownym wprowadzeniem bobra.

Muséum d'Histoire Naturelle,

Genève. 